\title{
Hereditary Hemorrhagic Telangiectasia: The ENT point of view
}

\author{
Phillipe Eloy ${ }^{1}$, Gabriela Musat ${ }^{2,3}$ \\ ${ }^{1}$ ENT Department, CHU UCL Namur, Namur, Belgium \\ ${ }^{2}$ ENT\&HNS Department, "Sfanta Maria" Hospital, Bucharest, Romania \\ 3"Carol Davila” University of Medicine and Pharmacy, Bucharest, Romania
}

\begin{abstract}
Hemorrhagic Hereditary Telangiectasia (HHT) disease, also called Osler-Weber-Rendu (OWR) disease, is a rare and underdiagnosed genetic disorder characterized by a multisystemic vascular dysplasia. Nosebleeds, acute or chronic digestive tract bleeding and various problems due to the involvement of major organs (liver, lungs, brain) characterize the disease.

Although it was described at the beginning of the 20th century, many patients, GPs and specialists still ignore the disease, its morbidities and the modalities of the treatment.

That is the reason why the authors have decided to publish this review on this familiar, evolving and potentially life-threatening disease, whose management can be sometimes a real nightmare for the clinician.
\end{abstract}

KEYWORDS: hereditary hemorrhagic telangiectasia, Osler-Weber-Rendu, telangiectasia, arterio-venous malformations, nosebleeds.

\section{INTRODUCTION}

Hemorrhagic Hereditary Telangiectasia (HHT) disease, also called Osler-Weber-Rendu (OWR) disease, is a rare and underdiagnosed genetic disorder characterized by a multisystemic vascular dysplasia. It is an autosomal dominant disorder with heterogeneous clinical presentation ${ }^{1}$. It is associated with a high plasmatic level of Transforming growth factor (TGF $\beta$ ) and Vascular endothelial growth factor (VEGF), leading to abnormalities in the angiogenesis. There is no abnormality of the haemostasis. Nosebleeds, acute or chronic digestive tract bleeding and various problems due to the involvement of major organs (liver, lungs, brain) characterize the disease. OWR disease is present all over the world. All racial and ethnic groups can be affected, but patients with a white skin seem to be more affected.

Although it was described at the beginning of the $20^{\text {th }}$ century by Henri Jules Louis Marie Rendu in $1896^{2}$, William Bart Osler in $1901^{3}$ and Frederick Parkes Weber in $1907^{4}$, many patients, GPs and specialists still ignore the disease, its morbidities and the modalities of the treatment ${ }^{5}$.

That is the reason why we have decided to publish this review on this familiar, evolving and potentially life-threatening disease, whose management can be sometimes a real nightmare for the clinician.

\section{HHT INCIDENCE AND ETIOPATHOGENESIS}

HHT is a rare disease, widely distributed, occurring in many ethnic groups around the world. The average worldwide prevalence is estimated to be between 1 in 5000 and 1 in 10000 people $^{1,5}$.

In Europe and Japan, the frequency is estimated to be between 1 in 5000 to 8000 persons. In France, the 
general incidence is from $1 / 6000$ to $1 / 8500$ and this counts for approximately 10000 patients. However, some regions are more involved, particularly in the Ain (incidence:1/1300), Jura (incidence: 1/2500) and Rhône-Alpes region (incidence: 1/8460) ${ }^{6,7}$.

In the world, there are some regions where the incidence is higher than elsewhere: in the Afro-Caribbean population of the Netherlands Antilles (Curacao Island and Bonaire; incidence: 1/1331), and Fionie Island (Funen) in Denmark (incidence:1/6500) ${ }^{8,9}$. This is explained by the founder effect.

HHT is inherited ${ }^{1,5-11}$. Usually, patients report that relatives (father, mother, grandparents, cousins, children) are known to have the disease, but a non-neglectable number of patients are unaware of the disease, its morbidity and treatment.

The mode of transmission is autosomal dominant with an extremely variable clinical expression.

OWR disease has an age-related penetration with complete expression by the age of 45 . The disease is not present at birth and $10 \%$ of the patients have experienced nosebleeds before the age of 10 . More than $50 \%$ of the patients have bled at the age of 20 and more than $90 \%$ have bled at the age of 45 . The disease has a great familiar predominance, but there are a lot of inter- and intrafamilial variations regarding the age of onset, the clinical presentation and the severity of the disease, even for the same genetic mutation.

The disease is characterized by generalized mucocutaneous telangiectasias and large visceral arterio-venous malformations associated with recurrent bleeding.

Telangiectasias are true arterio-venous communications without capillary network. They are present in the skin (lips, face, fingers, chest) and mucosa (nasal cavity, oral cavity, gastrointestinal tract, esophagus, stomach, small intestine and large bowel). Telangiectasias appear and increase in size with age.

Arterio-venous malformations are observed in visceral organs: the liver in 30 to $80 \%$, the lungs in 30 to $50 \%$ and the brain and the spine in 10 to $20 \%$. These malformations must be ruled out systematically in all patients with HHT.

The pathogenesis of HHT is poorly understood and some theories suggest that mutations in ENG (endoglin) or ACVRL1 (activin A receptor type IIlike 1), which are mostly expressed on endothelial cells, can lead to haploinsufficiency, causing an imbalance in the TGF $\beta$ and BMP signalling pathways $^{12-15}$. This imbalance leads to decreased TGF $\beta$ activation and increased VEGF production, the result being an excessive proliferation and migration of endothelial cells, resulting in reduced vessel maturation and thinning of the vascular wall.

\section{CLINICAL MANIFESTATIONS}

The most common symptom of HHT is nosebleed due to a rupture of a nasal telangiectasia $(95 \%$ of the consultations) $)^{1,5,12-15}$. This occurs at any age, but they are more common during puberty, pregnancy and menopause. Some favouring factors can be found: temperature, humidity, activity, sports, position. We can also find some food triggers such as alcohol intake, spices, food including salicylates. Nosebleeds are usually recurrent, despite the therapy. Sometimes they may be massive and life-threatening. Because of their frequency, they represent a permanent nuisance with great impact on the quality of life. They interfere with sports and social functioning. They often lead to iron deficiency, chronic anemia and possibility of heart failure. Blood transfusions are required in $10-30 \%$ of patients.

There are described other sources of bleeding represented by telangiectasias in the gastrointestinal tract, cutaneous telangiectasias or large arterio-venous malformations (AVMs) with different locations.

Telangiectasias in the gastrointestinal tract are present in more or less 15 to $30 \%$ of the patients, typically after the age of $40^{16}$. They are present in the stomach, the small and large intestine. $1 / 3$ of the patients bleed. The bleedings can be revealed by hematemesis or melena, or they can be slow, chronic, occult leading to fatigue, vertigo and visual disturbances.

The cutaneous telangiectasias are present in $75 \%$ of the HHT patients and increase in size and number with age. Typically, they are located in the lips, the oral mucosa, fingertips (Figure 1), the face (Figure 2), the chest. They are poorly symptomatic and most patients mentioned it because of a cosmetic reason.

Besides the telangiectasias, HHT patients may present with major lesions called arterio-venous malformations (AVMs). They are located in the liver, the lungs, the brain and the spine.

The liver AVMs (Figure 3) are present in $30 \%$ of the cases ${ }^{17}$. They are more common in the subtype HHT-2. There are 3 types of shunt: the one between the hepatic artery and the hepatic vein; between the hepatic artery and the portal vein; between the portal vein and the hepatic vein. Although usually asymptomatic, they can be associated with high flow heart failure, biliary impairment, hepatic ischemia and portal hypertension. Their diagnosis requires an imaging through MRI of the upper abdomen.

The lungs AVMs (Figure 4) are present in more or less $50 \%$ of the patients and sometimes as early as the puberty ${ }^{18,19}$. They can create right or left shunt causing complications such as, paradoxical embolisms, hypoxemia, high flow shortness of breath, cyanosis, pulmonary hypertension. They are known 


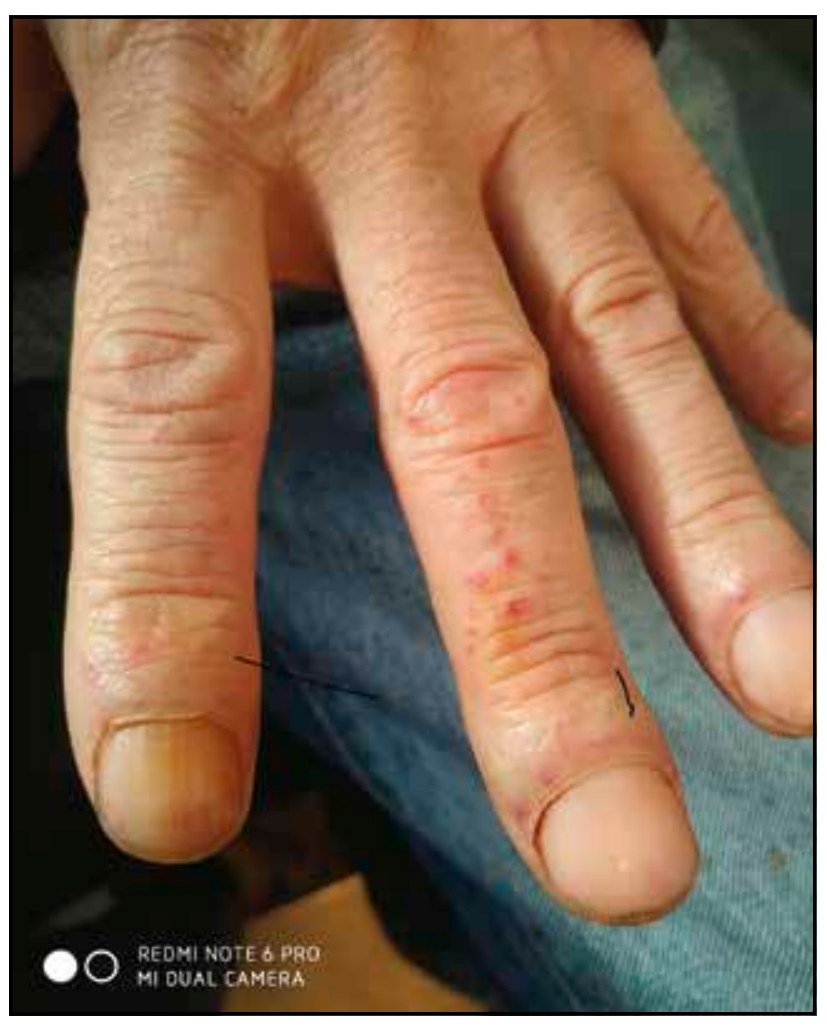

Figure 1. Cutaneous telangiectasias located at the fingers level.

as the classical cause of neurological complications such as strokes, brain abscess, thrombi, migraines. The best way to make their diagnosis is the thoracic scanner and a transthoracic echocardiography with bubbles. When present, prescription of antibiotics is necessary before any septic procedure (dental care). Diving is contraindicated. Filters are necessary for intravenous catheters.

About $10 \%$ of the patients with HHT have an intracerebral AVM (telangiectasia or AV fistula) ${ }^{20}$. The risk of bleeding is extremely rare $(0.5 \%$ per year) but the risk of mortality and severe morbidity associated to a rupture of the AVM is important and justifies the systematic screening of these AVMs, whatever the age of the patient.

Neurological complaints consist in stroke, headache, migraines, seizures, focal neurological symptoms, but usually they result from the pulmonary shunts with subsequent paradoxical embolisms. Migraines are more common in patients with OWR disease with or without pulmonary malformations. This can be explained by the presence of microthrombi, vasoactive substances release, such as serotonin in the central nervous system, or due to chronic hypoxemia.

Spine AVMs are relatively rare but may cause problems during pregnancy ${ }^{21}$. They must be ruled out in all pregnant women with a story of HHT.

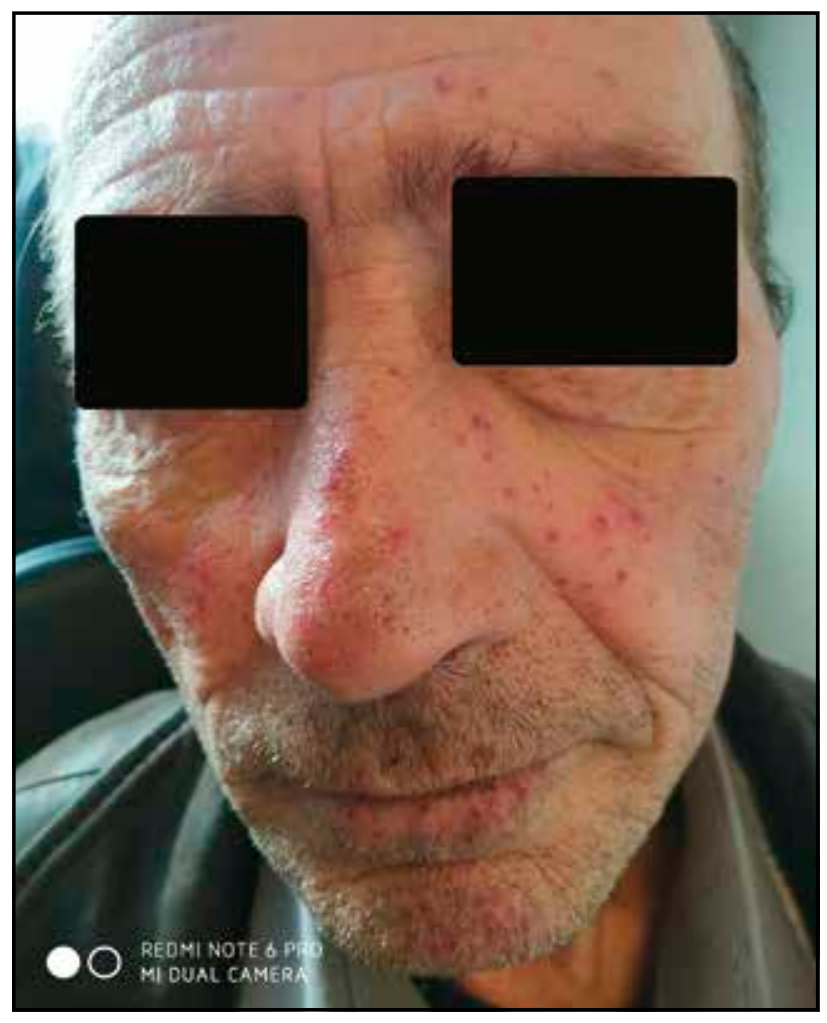

Figure 2. Cutaneous telangiectasias located in the face area.

\section{DIAGNOSIS OF HHT}

The diagnosis of HHT is based on clinical criteria (the Curaçao criteria) and genetics (molecular biology) ${ }^{11-14,22}$.

Clinically, the diagnosis of HHT is made on the basis of the Curaçao criteria, established in June 1999 by the Scientific Advisory Board of the HHT Foundation International, Inc. ${ }^{9}$.

There are four clinical diagnostic criteria ${ }^{22}$ :

1. Recurrent and spontaneous nosebleeds (mild to severe).

2. Multiple telangiectasias on the skin of the hands, lips or face, or inside of the nose or mouth.

3. Arteriovenous malformations or telangiectasias in one or more of the internal organs, including the lungs, brain, liver, intestines, stomach and the spinal cord.

4. A family history of HHT (first-degree relative such as brother, sister, parent or child who meets the criteria for definite HHT or has been genetically diagnosed).

The diagnosis of HHT is definite when there are at least 3 criteria, possible when there are only 2 criteria, and unlikely when there is only one.

Regarding the genetic aspects of the disease, mutations of 3 main genes are implicated in the HHT 


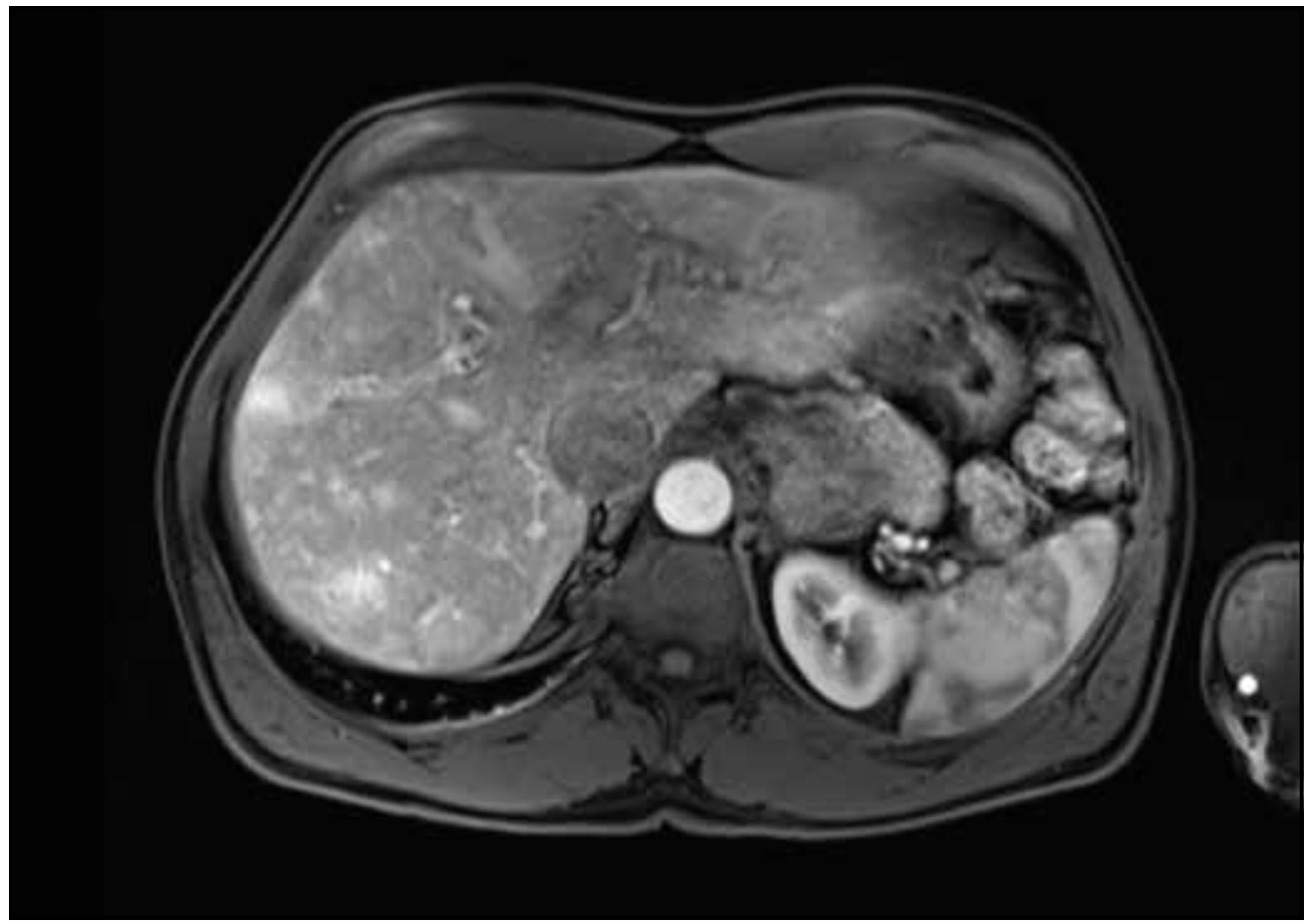

Figure 3. Liver arterio-venous malformations in a patient with HHT.

disease $\mathrm{e}^{11-15,21}$. The two major genes involved in the hereditary hemorrhagic telangiectasia are ENG gene (described in 1994), which codes for endoglin, a type 3 TGF $\beta$ receptor, and ACVRL1 gene (described in 1996), which codes for activin A receptor type II-like kinase 1 (ACVRL1), a type 1 TGF $\beta$ and a bone morphogenetic protein (BMP) receptor. The type 1 hereditary hemorrhagic telangiectasia (OMIM 187300) is related to the mutations in ENG and mutations in ACVRL1 lead to type 2 disease

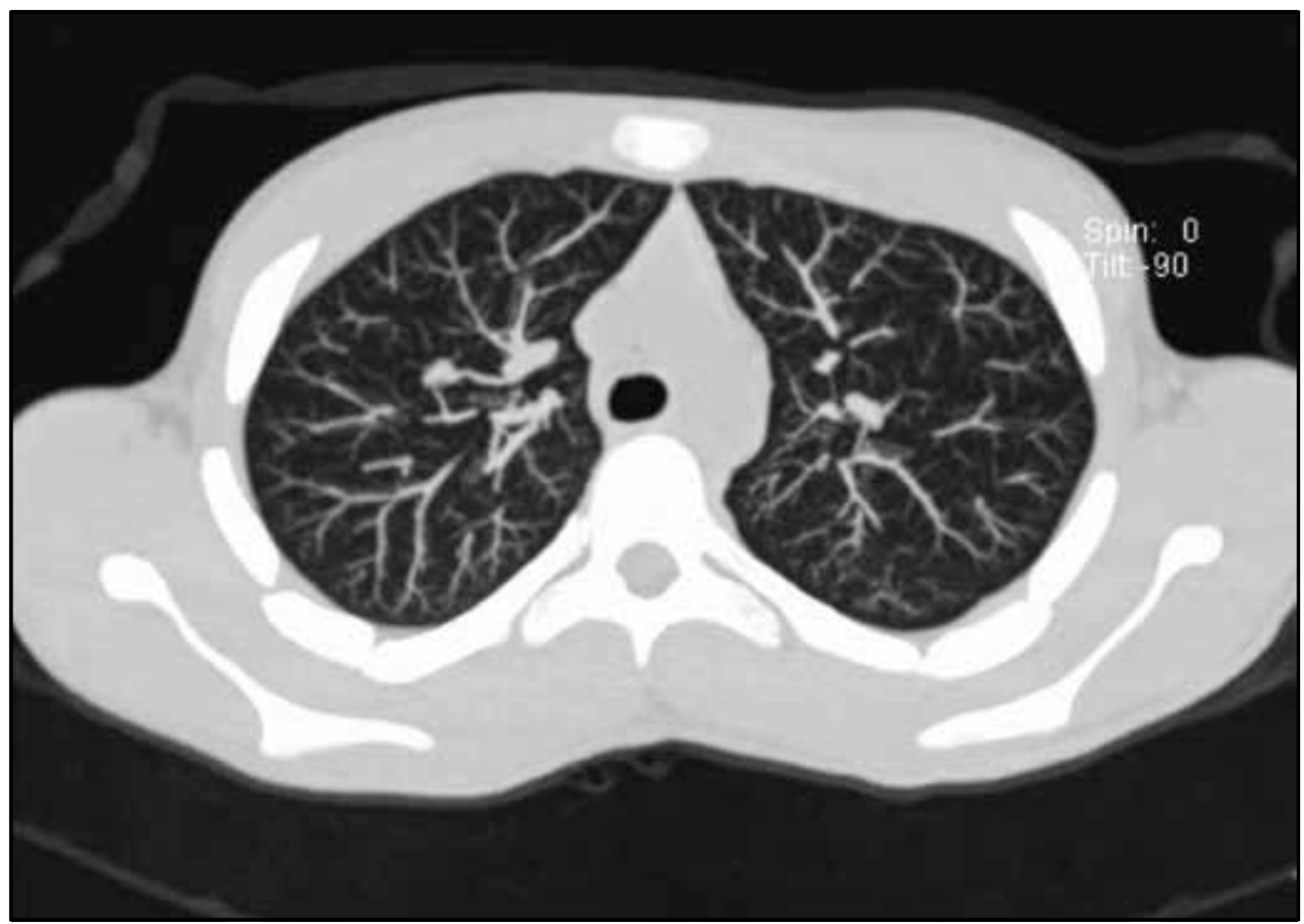

Figure 4. Lungs arterio-venous malformations in a patient diagnosed with HHT. 
(OMIM 600376). Mutations in other genes, such as MADH4 (also known as SMAD4) and BMP9 (also known as GDF2), are present in $2 \%$ or less of the cases. More than $80 \%$ of the patients with HHT have a disease-causing mutation in one of these genes that can be identified. $20 \%$ have clinical signs but no genetic mutation. $61 \%$ of HHT patients have the ENG mutation, $37 \%$ have the ACVRL1 mutation and $2 \%$ have the SMAD4 mutation.

However, there are more than 600 different mutations in the ENG and ACVRL1 groups.

There are some correlations between the clinics and genetics. The ENG mutation is associated with lung and cerebral AVMs. The ALK1 mutation is associated with hepatic and spinal malformations, nose bleeds and pulmonary hypertension, while the MADH4 is associated with a juvenile colic polyposis and pulmonary hypertension.

When a patient presents the characteristic lesions of the OWR disease, a complete mapping of the lesions must be done as early as possible. It comprises a thorough ENT examination, a pulmonary CT scan and a transthoracic echocardiography with bubbles, an angio-MRI of the superior abdomen, cerebral MRI, and a spinal evaluation by MRI in female candidates for pregnancy. A blood test is mandatory to detect iron deficiency or anemia and its severity. In case of unexplained anemia, gastrointestinal assessment is mandatory (gastroscopy, colonoscopy, video capsule) as early as the age of 35 . In case of juvenile polyposis and HHT-3, a gastrointestinal follow-up at regular intervals is necessary because of the risk of development of colorectal neoplasia. Last but not least, when available, a genetic screening must be proposed for all the patients with HHT, relatives, family and for all patients suspected to have the disease.

\section{THE MANAGEMENR OF OSLER-WEBER- RENDU DISEASE}

The management of the OWR disease must be multidisciplinary ${ }^{11,23,24}$. It is important to know who the coordinator is in order to centralize and coordinate the workup and management. We must point out that there is not a single optimal treatment.

A. The first step comprises a control of the iron deficiency and anemia. At the beginning, oral iron supplements are enough. In more severe cases intravenous administration of iron is required. In advanced cases, red cells transfusion can be necessary, but we must take into account the risks of infections and sensitizations with severe allergic reactions. Erythropoietin can be administered in Jehovah witnesses.

\section{B. Prevention of bleeding}

It consists to humidify the airflow with regular application of lubricants: nasal cream (Vitapantol, Rhinovita, Aacifemine) to prevent crusting and dryness.

It is also important to avoid injury to the nasal mucosa (the patient should not blow his nose too hard). Some foods are prohibited because they include high doses of salicylates (red wine, spices, chocolate, coffee) or have some antiplatelet activity (garlic, ginkgo-biloba, ginseng), food with high dose of Omega 3 (salmon).

C. Non-instrumental methods to reduce bleeding:

\section{Medication}

\section{Topical application of Propranolol}

Propranolol has been shown, by Mei-Zahav et al., to have antiangiogenic properties in vitro and in vivo and is commonly used to treat hemangiomas ${ }^{25}$. This reference is a retrospective case series of $6 \mathrm{pa}-$ tients with HHT who were treated with $0.5 \mathrm{~cm}^{3}$ of $1.5 \%$ propranolol gel, applied to each nostril twice daily for at least 12 weeks. The authors found a significant improvement in the epistaxis severity score in all patients. Hemoglobin level increased significantly, and the mean number of blood transfusions decreased. No significant side effects of the treatment were recorded. A prospective controlled trial is required to confirm these findings.

\section{Antifibrinolytics}

Tranexamic acid (Exacyl) is the most common medication used in the daily practice for the management of nosebleeds ${ }^{26-28}$. It has the property to inhibit fibrinolysis and reduces the expression of endoglin and ALK1. Studies demonstrate a significant reduction in the duration of epistaxis per months without any side effects. Patients taking tranexamic acid at a dose of $3 \mathrm{~g}$ /day had decreased durations of average daily bleeding compared to patients taking placebo. However, tranexamic acid had no effect on patient's hemoglobin level, and many patients in the tranexamic acid treatment group reported common side effects such as vertigo and diarrhea ${ }^{28}$.

In case of past history of thromboembolic attacks, caution is mandatory.

\section{Estrogens and progesterone}

Ethinyl estradiol, norethindrone or mestranol have been used in OWR disease with significant reduction of nose bleeding ${ }^{29}$. They lead to a hyperplasia of the nasal epithelium, protecting the lesions from trauma. They can be used orally with a risk of gynecomastia, loss of libido (in men), increase of weight and coronary problems and venous thrombosis. This mode of administration is rarely used because of the side effects. An alternative is to use it as a cream. Aacifemine seems to be effective in a significant number of cases.

\section{Thalidomide}

Thalidomide was a very effective medication in 
the $50 \mathrm{~s}$ to treat nausea and vomiting in pregnant women. But it was known to interfere with the angiogenesis leading to the development of more than 10000 cases of phocomelia. It is an anti-TNF- $\alpha$ molecule which stimulates the maturation of the walls of the vessels. Some experiments and clinical studies have demonstrated its efficacy in OWR disease. The efficacy is dose dependant. The starting dose is $50 \mathrm{mg} /$ day. It is increased by $50 \mathrm{mg} /$ day every four weeks until response to a maximum dose of $200 \mathrm{mg}$ / day $^{30-33}$. Treatment induces a significant decrease in the severity and frequency of bleeding with increased hemoglobin levels and great reduction in transfusions ${ }^{30,33}$. This agent should be used with great caution given its thrombogenicity. Actually, some adverse events are well known such as drowsiness, constipation, asthenia and peripheral sensory neuropathy ${ }^{31,32}$. But the major one is the development of deep venous thrombosis ${ }^{34}$. Therefore, the medication is recommended only for severe forms of OWR disease with refractory epistaxis.

\section{Tamoxifen}

It is a selective modulator for oestrogen receptors (anti oestrogens). It is used orally for breast cancer. Two studies have demonstrated good outcomes, with consecutive studies evaluating the benefit of tamoxifen $20 \mathrm{mg}$ /day in patients with $\mathrm{HHT}^{35,36}$. Both studies were undertaken in Israel, where an initial group of 21 patients with HHT was enrolled in a double-blind, placebo-controlled clinical trial in which 10 patients were treated with tamoxifen and 11 were treated with placebo $^{35}$. The patients were evaluated at 6 months, and the group taking tamoxifen reported a statistically significant decrease in the severity of bleeding. The results were quantified via examination of the amount of telangiectasia and the patients' opinions on severity rather than on a measurable scale. These 21 patients continued into a cohort trial with an additional 25 patients to evaluate the long-term effects of treatment ${ }^{36}$. All the patients were treated with tamoxifen $20 \mathrm{mg}$ /day and completed follow-up with evaluation of their hemoglobin levels; completion of the Rhinosinusitis Disability Index; recorded bleeding time, frequency of bleeding, and number of transfusions during the previous month. The mean duration of follow-up was 23 months, at which time the investigators found statistically decreased mean bleeding times and increased hemoglobin levels compared to the patients' pre-treatment values. Eight patients were lost to follow-up for various reasons. Importantly, 3 patients did not improve with the treatment, and 1 female patient had ultrasound-diagnosed uterine mucosal hypertrophy that resolved with treatment cessation. Nevertheless, the study showed clear statistical improvement in symptoms compared to initially documented symptoms, and no other patients were reported to have side effects from the treatment.

However, this use of tamoxifen requires further trials with long-term follow-up to appropriately investigate the use of this treatment for a lifelong disease. Some side effects can be observed, such as changes in mood, facial flush, but mostly the risk of deep venous thrombosis, pulmonary embolisms and increased incidence of uterine cancers.

\section{Bevacizumab}

Bevacizumab (Avastin ${ }^{\circledR}$ ) is a monoclonal antibody, recombinant anti VEGF used in oncology. Many studies, mainly case series, have been reported and demonstrated a reduction in nosebleeds in refractory epistaxis. The modalities of administration vary, from systemic (IVD) to topical (local injection) administration. The preliminary results were very encouraging ${ }^{37,38}$, but RCT studies and metaanalysis did not confirm the results ${ }^{39}$.

For example, this reference published in Rhinology $^{39}$ collected thirteen studies (four randomised controlled trials, three prospective studies, three retrospective studies, one case series and two case reports) with a total of 357 patients. The study results showed that local administration (submucosal injection or topically) of bevacizumab did not have a significant impact on epistaxis duration, frequency, severity or quality of life compared to placebo or other local treatments. They conclude that "intranasal bevacizumab treatment does not have a significant effect on epistaxis in patients with HHT. There are several limitations that require further investigation to confidently rule out local bevacizumab as an effective therapy in HHT related epistaxis" 39 . Side effects such as septal perforation have been reported. This medication is no longer used for the treatment of OWR disease.

\section{7. $N$-Acetylcysteine}

Although its indication must be confirmed by RCT, N-acetylcysteine at the dosage of $600 \mathrm{mg}$ TID for 12 weeks has been proved to be effective in patients with moderate OWR disease and particularly with the phenotype 1 (ENG mutation $)^{40}$.

\section{Haemostatic gels}

Surgiflo ${ }^{\circledR}$ is a dehydrated gelatin-thrombin matrix, currently used in neurosurgery and in thoracic and vascular surgery ${ }^{41-43}$, which recently has been proposed as an alternative to nasal packing after functional endoscopic sinus surgery ${ }^{41}$ and in the management of recurrent epistaxis ${ }^{42}$. A recent publication reports some advantages to use it in case of HHT as an alternative to more invasive techniques ${ }^{43}$. The cost of the product may be a limitation to its use, but it is widely offset by the reduction of hospitalization.

Floseal haemostatic matrix (Floseal®), another device used to control severe epistaxis, is a haemostatic 
agent that consists of two major components: gelatin granules that swell when they come into contact with blood or other wet surfaces, creating a tamponade effect, and a high concentration of human thrombin that promotes natural clot formation by converting fibrinogen to fibrin. Floseal ${ }^{\circledR}$ has a hydrophilic property and, therefore, adheres well to wet tissues. It is indicated for use as an adjunct surgical haemostat. Recently, the product has been used with success in patients with $\mathrm{HHT}^{44}$.

\section{Instrumental measures}

The management of acute epistaxis implies the use of instrumental measures.

Nasal packing is the first line treatment in case of acute epistaxis. It must be done meticulously, gently, in an atraumatic way, with resorbable products (Surgicel®) to avoid increase or repetition of bleeding when the packing is retrieved.

Cauterizations can be performed with chemical agents $\left(\mathrm{AgNo}_{3}\right)$, the monocautery or the bipolar.

Laser photocoagulation, performed under local or general anaesthesia, has been used in case of mild or moderate nosebleeds. Different wavelengths have been used, such as potassium titanyl phosphate (KTP) laser, Nd-Yag laser (wavelength $1064 \mathrm{~nm}$ ) or the diode laser. Laser transmitted through optical fibre is preferred. They can be used deeper in the nasal cavities under endoscopic guidance. Laser shooting can be done directly on the telangiectasias or around these (recommended) on a noncontact mode. They can vaporize the angiomas or create a fibrosis.

Argon plasma coagulation, which is not a laser, consists in the delivery of a high voltage spark at the tip of the probe that ionizes the argon gas as it is sprayed from the probe tip in the direction of the target tissue. The study published by Pagella, in 2013, including 26 patients suffering from severe epistaxis requiring blood transfusions, demonstrated a significant reduction in intensity, frequency and duration of the nosebleeds with a significant decrease in the number of transfusions ${ }^{45}$.

Submucosal radiofrequency is promising. It seems less traumatic than the electrical or chemical cauterization, preserving the nasal mucosa. Mortuaire et al. published in 2013 a study including 16 patients treated with the radiofrequency under local anaesthesia ${ }^{46}$. The power settings were the following: 10 watts - 5 sec - 50 joules. He observed a reduction in the duration of the nosebleeds in $2 / 3$ of the cases and a reduction in the frequency of nosebleeds. Thirteen of the 16 patients were satisfied with the technique and would request it for subsequent procedures to treat their nasal bleedings.

Coblation has also been used to cauterize telangiectasia in $\mathrm{HHT}^{47}$.

The treatment of epistaxis with cauterization, whatever the device used, can lead to numerous complications, such as septal perforation with subsequent crusting, whistling and epistaxis. Staphylococcus infections can occur after nasal packing. All these side effects have great impact (deterioration) on the patient's quality of life and they must be minimized as much as possible.

Superselective embolization or arterial ligation can also be used. Sphenopalatine and facial arteries can be embolized. The efficacy is moderate and limited in duration. They are associated with risks and adverse events: stroke, blindness, pain or necrosis of the velum.

\section{E. Surgical methods}

\section{Septodermoplasty}

Saunders' procedure is an old technique first described in 1960. It consists of a resection of the septal mucosa and covering the defect with a piece of skin. The procedure must be done in one side to prevent septal perforation. In good hands, it is effective in reducing the frequency and severity of nosebleeds and improves significantly the quality of life $\mathrm{e}^{48,49}$. However, it is not without side effects, such as nasal crusting, nasal odour, decrease in the sense of smell and worsened sinus infections ${ }^{49}$. Nowadays, it is less performed than in the past due to these side effects, but also because recurrences are observed in the short term. Colonization of the graft (in and around) by the telangiectasias has been observed in the short term.

\section{2. «Young's procedure» - Nasal closure}

In case of refractory epistaxis resistant to all the treatments mentioned before and necessitating repeated blood cell transfusions, obliteration of the nasal cavities can be an option. Valerie Lund published in 2017 an impressive number of cases. The procedure was done in 100 patients and the success rate was estimated to be $94 \%^{50}$. The lack of smell and taste was the most frequent complaint. In the literature, there are some isolated cases of bleeding persistent despite the procedure, requiring a reopening of the nasal cavities ${ }^{51}$. In our experience, it is not so easy to convince the patients to undergo the procedure because nasal obstruction is badly supported.

What about the management of the other major lesions? This is out of the scope of the paper, but we can briefly summarize the options. The pulmonary AVMs are usually treated by interventional radiology. Antibioprophylaxis is always necessary for dental cares or any type of surgery and filters must be used for intravenous lines. For these patients, diving and scuba are prohibited.

Even if they are rare and paucisymptomatic, the cerebral AVMs must be ruled out and monitored. Surgery is rarely necessary. Typically, neurological symptoms come from other lesions such as pulmonary or hepatic shunts.

In case of liver AVMs, interventional radiology is 
the treatment of choice, surgery being necessary in selective cases.

The gastrointestinal telangiectasias are frequent and represent the second cause of bleeding. In patients diagnosed with this pathology, coagulation (LASER/Argon plasma) is often necessary.

\section{PROGNOSTIC}

The life expectancy is not reduced compared to the general population. The survival is the same, after the age of 60 . The morbidity is higher in the group below 60. Approximately $10 \%$ die due to severe complications. Pulmonary AVMs and gastrointestinal tract bleeding can be life-threatening risks. Coronary problems are not more frequent in the OWR disease group. There is no more risk to develop a malignancy except in the group of HHT-3.

Pregnancy is not an absolute contraindication in HHT patients, but monitoring is necessary as pregnancy may have some risks. It is lethal in $1 \%$ due to pulmonary AVMs, cerebral haemorrhage, thromboembolic complications. A multidisciplinary workup is necessary. An MRI to rule out spinal malformation is required in the 3rd trimester. The delivery can be done via the natural ways.

Prescription of antiaggregant can be challenging. The lowest effective dosage is highly recommended.

\section{CONCLUSIONS}

Hereditary Hemorrhagic Telangiectasia is an inherited autosomal dominant disease. It is characterized by mucocutaneous telangiectasias and AVMs. The clinical presentation changes with age, nose bleeds being the most frequent complaint followed by gastrointestinal bleeding. Iron deficiency and anemia are the consequences of the bleedings.

A complete clinical assessment is mandatory.

A genetic screening is recommended for the patients and their relatives.

Management should require a multidisciplinary approach, the ENTs having an important place in the diagnosis and treatment. There is not a single therapy. The evolution is extremely variable, capricious and sometimes life-threatening. The control of bleeding, of iron deficiency and antibioprophylaxis, before any instrumental methods, are of upmost importance.

Conflict of interests: The authors report no conflicts of interest.

Contribution of authors: All authors have equally contributed to this work.

\section{REFERENCES}

1. Guttmacher AE, Marchk DA, White RI Jr. Hereditary hemorrhagic telangiectasia. N Engl J Med. 1995;333(14):918-24.

2. Rendu HJLM. Épistaxis répétées chez un sujet porteur de petits angiomes cutanés et muqueux. Bull Soc med Hosp. 1896;13:731-3.

3. Osler W. On a family form of recurring epistaxis, associated with multiple telangiectases of the skin and mucous membranes. Bull Johns Hopkins Hosp. 1901;12:333-7.

4. Weber FP. Multiple hereditary developmental angiomata (telangiectases) of the skin and mucous membranes associated with recurring haemorrhages. Lancet. 1907;2:160-2.

5. Puente RZ, Bueno J, Salcedo M, Cuesta JM, Marqués S, Menendez C, et al. Epidemiology of Hereditary Haemorrhagic Telangiectasia (HHT) in Spain. Hereditary Genet. 2016;5(3):173. DOI:10.4172/2161-1041.1000173.

6. Govani FS, Shovlin CL. Hereditary haemorrhagic telangiectasia: a clinical and scientific review. Eur J Hum Genet. 2009;17(7):860-71. DOI 10.1038/ejhg.2009.35. Epub 2009 Apr 1.

7. Lesca G, Genin E, Blachier C, Olivieri C, Coulet F, Brunet G, et al. Hereditary hemorrhagic telangiectasia: evidence for regional founder effects of ACVRL1 mutations in French and Italian patients. Eur J Hum Genet. 2008;16(6):742-9. DOI: 10.1038/ejhg.2008.3. Epub 2008 Feb 20.

8. Kjeldsen AD, Vase P, Green A. Hereditary haemorrhagic telangiectasia: a population-based study of prevalence and mortality in Danish patients. J Intern Med. 1999;245(1):31-9.

9. Westermann CJ, Rosina AF, De Vries V, de Coteau PA. The prevalence and manifestations of hereditary hemorrhagic telangiectasia in the AfroCaribbean population of the Netherlands Antilles: a family screening. Am J Med Genet A. 2003;116A(4):324-8.

10. Jessurun GA, Kamphuis DJ, van der Zande FH, Nossent JC. Cerebral arteriovenous malformations in The Netherlands Antilles. High prevalence of hereditary hemorrhagic telangiectasia-related single and multiple arteriovenous malformations. Clin Neurol Neurosurg. 1993;95(3):193-8.

11. Faughnan ME, Palda VA, Garcia-Tsao G, Geisthoff UW, McDonald J, Proctor DD, et al. International guidelines for the diagnosis and management of hereditary haemorrhagic telangiectasia. J Med Genet. 2011;48(2):73-87. DOI: 10.1136/jmg.2009.069013. Epub 2009 Jun 23.

12. McDonald J, Bayrak-Toydemir P, Pyeritz RE. Hereditary hemorrhagic telangiectasia: an overview of diagnosis, management, and pathogenesis. Genet Med. 2011;13(7):607-16. DOI: 10.1097/GIM.0b013e3182136d32.

13. Duffau P, Lazarro E, Viallard JF. Hereditary hemorrhagic telangiectasia. Rev Med Interne. 2014;35(1):21-7. DOI: 10.1016/j.revmed.2013.02.022. Epub 2013 Mar 19.

14. Lee ST, Kim JA, Jang SY, Kim DK, Do YS, Suh GY, et al, Clinical features and mutations in the ENG, ACVRL1, and SMAD4 genes in Korean patients with hereditary hemorrhagic telangiectasia. J Korean Med Sci. 2009;24(1):69-76. DOI: 10.3346/jkms.2009.24.1.69.

15. Shovlin CL Hereditary hemorrhagic telangiectasia: pathophysiology, diagnosis and treatment. Blood Rev. 2010;24(6):203-19. DOI: 10.1016/j. blre.2010.07.001. Epub 2010 Sep 25.

16. Jackson SB, Villano NP, Benhammou JN, Lewis M, Pisegna JR, Padua D. Gastrointestinal manifestations of hereditary hemorrhagic telangiectasia (HHT): a systematic review of the literature. Dig Dis Sci. 2017;62(10):262330. DOI:10.1007/s10620-017-4719-3. Epub 2017 Aug 23.

17. Garcia-Tsao G. Liver involvement in hereditary hemorrhagic telangiectasia (HHT). J Hepatol. 2007;46(3):499-507.

18. Dupuis-Girod S, Cottin V, Shovlin CL. The lung in hereditary hemorrhagic telangiectasia. Respiration. 2017;94(4):315-30. DOI 10.1159/000479632. Epub 2017 Aug 30.

19. Narsinh KH, Ramaswamy R, Kinney TB. Management of pulmonary arteriovenous malformations in hereditary hemorrhagic telangiectasia patients. 
Semin Intervent Radiol. 2013;30(4):408-12. DOI: 10.1055/s-0033-1359736.

20. Brinjikji W, Iyer VN, Wood CP, Lanzino G. Prevalence and characteristics of brain arteriovenous malformations in hereditary hemorrhagic telangiectasia: a systematic review and meta-analysis. J Neurosurg. 2017;127(2):302-10. DOI: 10.3171/2016.7.JNS16847. Epub 2016 Oct 21.

21. Brinjikji W, Nasr DM, Cloft HJ, Iyer VN, Lanzino G. Spinal arteriovenous fistulae in patients with hereditary hemorrhagic telangiectasia: A case report and systematic review of the literature. Interv Neuroradiol. 2016;22(3):354-61. DOI: 10.1177/1591019915623560. Epub 2016 Jan 27.

22. Shovlin CL, Guttmacher AE, Buscarini E, Faughnan ME, Hyland RH, Westermann CJ, et al. Diagnostic criteria for hereditary hemorrhagic telangiectasia (Rendu-Osler-Weber syndrome) Am J Med Genet. 2000;91(1):66-7.

23. Zarrabeitia R, Albiñana V, Salcedo M, Señaris-Gonzalez B, FernandezForcelledo JL, Botella LM. A Review on Clinical management and pharmacological therapy on hereditary haemorrhagic telangiectasia (HHT). Cur Vasc Pharmacol. 2010;8(4):473-81.

24. Garg N, Khunger M, Gupta A, Kumar N. Optimal management of hereditary hemorrhagic telangiectasia. J Blood Med. 2014;5:191-206. DOI: 10.2147/JBM.S45295.

25. Mei-Zahav M, Blau H, Bruckheimer E, Zur E, Goldschmidt N. Topical propranolol improves epistaxis in patients with hereditary hemorrhagic telangiectasia - a preliminary report. J Otolaryngol Head Neck Surg. 2017;46(1):58. DOI: 10.1186/s40463-017-0235-x.

26. Gaillard S, Dupuis-Girod S, Boutitie F, Riviere S, Moriniere S, Hatron PY, et al. Tranexamic acid for epistaxis in hereditary hemorrhagic telangiectasia patients: a European cross-over controlled trial in a rare disease. J Thromb Haemost. 2014;12(9):1494-502. DOI: 10.1111/jth.12654. Epub 2014 Jul 29.

27. Geisthoff UW, Seyfert UT, Kübler M, Bieg B, Plinkert PK, KönigJ. Treatment of epistaxis in hereditary hemorrhagic telangiectasia with tranexamic acid - a double-blind placebo-controlled cross-over phase IIIB study. Thromb Res. 2014;134(3):565-71. DOI: 10.1016/j. thromres.2014.06.012. Epub 2014 Jun 16.

28. 28. Sabbà C, Gallitelli M, Palasciano G. Efficacy of unusually high doses of tranexamic acid for the treatment of epistaxis in hereditary hemorrhagic telangiectasia. N Engl J Med. 2001;345:926. DOI: 10.1056/ NEJM200109203451216.

29. Jameson JJ, Cave DR. Hormonal and antihormonal therapy for epistaxis in hereditary hemorrhagic telangiectasia. Laryngoscope. 2004;114(4):705-9.

30. Fang J, Chen X, Zhu B, Ye H, Zhang W, Guan J, et al. Thalidomide for epistaxis in patients with hereditary hemorrhagic telangiectasia: a preliminary study. Otolaryngol Head Neck Surg. 2017;157(2):217-21. DOI: 10.1177/0194599817700573. Epub 2017 Apr 18.

31. Lebrin F, Srun S, Raymond K, Martin S, van den Brinks S, Freitas C, et al. Thalidomide stimulates vessel maturation and reduces epistaxis in individuals with hereditary hemorrhagic telangiectasia. Nat Med. 2010;16(4):420-8. DOI: 10.1038/hm.2131. Epub 2010 Apr 4.

32. Franchini M, Frattini F, Crestani S, Bonfanti C. Novel treatments for epistaxis in hereditary hemorrhagic telangectasia: a systematic review of the clinical experience with thalidomide. J Thromb Thrombolysis. 2013;36(3):355-7. DOI: 10.1007/s11239-012-0840-5.

33. Invernizzi R, Quaglia F, Klersy C, Pagella F, Ornati F, Chu F, et al. Efficacy and safety of thalidomide for the treatment of severe recurrent epistaxis in hereditary haemorrhagic telangiectasia: results of a non-randomised, single-centre, phase 2 study. Lancet Haematol. 2015;2(11):e465-73. DOI 10.1016/S2352-3026(15)00195-7. Epub 2015 Oct 27.

34. Penaloza A, Vekemans MC, Lambert C, Hermans C. Deep vein thrombosis induced by thalidomide to control epistaxis secondary to hereditary haemorrhagic telangiectasia. Blood Coagul Fibrinolysis. 2011;22(7):6168. DOI: 10.1097/MBC.0b013e32834a040c.

35. Yaniv E, Preis M, Hadar T, Shvero J, Haddad M. Antiestrogen therapy for hereditary hemorrhagic telangiectasia: a double-blind placebo-controlled clinical trial. Laryngoscope. 2009;119(2):284-8. DOI: 10.1002/ lary.20065.

36. Yaniv E, Preis M, Shevro J, Nageris B, Hadar T. Anti-estrogen therapy for hereditary hemorrhagic telangiectasia - a long-term clinical trial. Rhinology. 2011;49(2):214-6. DOI: 10.4193/Rhino09.201.

37. Dheyauldeen S, Østertun Geirdal A, Osnes T, Vartdal LS, Dollner R. Bevacizumab in hereditary hemorrhagic telangiectasia-associated epistaxis: effectiveness of an injection protocol based on the vascular anatomy of the nose. Laryngoscope. 2012;122(6):1210-4. DOI: 10.1002/ lary.23303. Epub 2012 May 7.

38. Kini SD, Yiu DW, Weisberg RA, Davila JF, Chelius DC. Bevacizumab as treatment for epistaxis in hereditary hemorrhagic telangiectasia: a literature review. Ann Otol Rhinol Laryngol. 2019;128(5):467-71. DOI: 10.1177/0003489419826139. Epub 2019 Jan 29.

39. Stokes P, Rimmer J. Intranasal bevacizumab in the treatment of HHT -related epistaxis: a systematic review. Rhinology. 2018;56(1):3-10.

40. de Gussem EM, Snijder RJ, Disch FJ, Zanen P, Westermann CJ, Mager JJ. The effect of $\mathrm{N}$-acetylcysteine on epistaxis and quality of life in patients with HHT: a pilot study. Rhinology. 2009;47(1):85-8.

41. Woodworth BA, Chandra RK, LeBenger JD, Ilie B, Schlosser RJ. A gelatin-thrombin matrix for hemostasis after endoscopic sinus surgery. Am J Otolaryngol. 2009;30(1):49-53. DOI: 10.1016/j.amjoto.2007.11.008. Epub 2008 Jun 16.

42. Buiret G, Pavic M, Pignat JC, Pasquet F. Gelatin-thrombin matrix: a new and simple way to manage recurrent epistaxis in hematology units. Case Rep Otolaryngol. 2013;2013:851270. DOI: 10.1155/2013/851270. Epub 2013 May 23.

43. Catone E, Marino A, Castagna G, Sicignano S, Rega F, Di Rubbo V, et al. A novel approach to manage recurrent epistaxis in outpatients with hereditary hemorrhagic telangiectasia. Am J Emerg Med. 2014;32(8):952. E1-952.E2. DOI: 10.1016/j.ajem.2014.02.005.

44. Warner L, Halliday J, James K, de Carpentier J. Domiciliary floseal prevents admission for epistaxis in hereditary hemorrhagic telangiectasia. Laryngoscope. 2014;124(10):2238-40. DOI: 10.1002/lary.24701. Epub 2014 May 2.

45. Pagella F, Matti E, Chu F, Pusateri A, Tinelli C, Olivieri C, et al. Argon plasma coagulation is an effective treatment for hereditary hemorrhagic telangiectasia patients with severe nosebleeds. Acta Otolaryngol. 2013;133(2):174-80. DOI: 10.3109/00016489.2012.718097. Epub 2012 Oct 15.

46. Mortuaire G, Boute O, Hatron PY, Chevalier D. Pilot study of submucosal radiofrequency for epistaxis in hereditary hemorrhagic telangiectasia. Rhinology. 2013;51(4):355-60. DOI: 10.4193/Rhin13.027.

47. Poetker DM. Endoscopic-guided coblation treatment of nasal telangiectasias in hereditary hemorrhagic telangiectasia: "How I do it". Am J Rhinol Allergy. 2017;31 (3):205-6. DOI: 10.2500/ajra.2017.31.4427.

48. Fiorella ML, Ross D, Henderson KJ, White RI Jr. Outcome of septal dermoplasty in patients with hereditary hemorrhagic telangiectasia. Laryngoscope. 2005;115(2):301-5.

49. Levine CG, Ross DA, Henderson KJ, Leder SB, White RI Jr. Long-term complications of septal dermoplasty in patients with hereditary hemorrhagic telangiectasia. Otolaryngol Head Neck Surg. 2008;138(6):721-4. DOI: 10.1016/j.otohns.2008.01.005.

50. Lund VJ, Darby Y, Rimmer J, Amin M, Husain S. Nasal closure for severe hereditary haemorrhagic telangiectasia in 100 patients. The Lund modification of the Young's procedure: a 22-year experience. Rhinology. 2017;55(2):135-41. DOI: 10.4193/Rhin16.315.

51. Ting JY, Remenschneider A, Holbrook EH. Management of severe epistaxis after Young's procedure: a case report. Int Forum Allergy Rhinol. 2013;3(4):334-7. DOI: 10.1002/alr.21099. Epub 2012 Oct 25 